\title{
The diagnostic accuracy of clinical tests for anterior cruciate ligament tears are comparable but the Lachman test has been previously overestimated: a systematic review and meta-analysis
}

\author{
Pawel A. Sokal ${ }^{1,2} \cdot$ Richard Norris $^{1,3} \cdot$ Thomas W. Maddox ${ }^{1,4} \cdot$ Rachel A. Oldershaw $^{1}$ (D)
}

Received: 20 September 2021 / Accepted: 20 January 2022 / Published online: 12 February 2022

(c) The Author(s) 2022

\begin{abstract}
Purpose The diagnostic accuracy of clinical tests for anterior cruciate ligament injury has been reported in previous systematic reviews. Numerous studies in these reviews include subjects with additional knee ligament injury, which could affect the sensitivity of the tests. Meta-analyses have also been performed using methods that do not account for the non-independence of sensitivity and specificity, potentially overestimating diagnostic accuracy. The aim of this study was to report the diagnostic accuracy of clinical tests for anterior cruciate ligament tears (partial and complete) without concomitant knee ligament injury. Methods A systematic review with meta-analysis was performed according to the PRISMA guidelines. Meta-analyses included studies reporting the specificity and/or sensitivity of tests with or without concomitant meniscal injury. Where possible, pooled diagnostic estimates were calculated with bivariate random-effects modelling to determine the most accurate effect sizes. Diagnostic accuracy values are presented for the anterior drawer, Lachman, Lever sign and pivot shift tests overall and in acute or post-acute presentations.

Results Pooled estimates using a bivariate model for overall sensitivity and specificity respectively were as follows: anterior drawer test 83\% [95\% CI, 77-88] and 85\% [95\% CI, 64-95]; Lachman test 81\% [95\% CI, 73-87] and 85\% [95\% CI, 73-92]; pivot shift test 55\% [95\% CI, 47-62] and 94\% [95\% CI, 88-97]; Lever sign test 83\% [95\% CI, 68-92] and 91\% [95\% CI, 83-95]. For specific presentations, the sensitivity and specificity of the Lachman test, respectively, were: complete tears $68 \%$ [95\% CI, 54-79] and 79\% [95\% CI, 51-93]; post-acute injuries 70\% [95\% CI, 57-80] and 77\% [95\% CI, 53-91].

Conclusions The pivot shift and Lever sign were the best tests overall for ruling in or ruling out an anterior cruciate ligament tear, respectively. The diagnostic accuracy of the Lachman test, particularly in post-acute presentations and for complete tears, is lower than previously reported. Further research is required to establish more accurate estimates for the Lachman test in acute presentations and partial ligament tears using bivariate analysis.
\end{abstract}

Level of evidence III.

Keywords ACL $\cdot$ ACL tear $\cdot$ Clinical diagnostic tests $\cdot$ Knee injuries $\cdot$ Sporting injuries $\cdot$ Anterior drawer $\cdot$ Pivot shift · Lever sign $\cdot$ Lachman $\cdot$ Meta-analysis

Rachel A. Oldershaw

rachel.oldershaw@liverpool.ac.uk

1 Department of Musculoskeletal and Ageing Science, Institute of Life Course and Medical Sciences, Faculty of Health and Life Sciences, University of Liverpool, William Henry Duncan Building, 6 West Derby Street, Liverpool L7 8TX, UK

2 Department of Medicine, School of Medicine, University of Liverpool, Liverpool L69 3GE, UK
3 Department of Trauma and Orthopaedics, Aintree University Hospital, Liverpool University Hospitals NHS Foundation Trust, Lower Lane, Fazakerley, Liverpool L9 7AL, UK

4 Small Animal Teaching Hospital, Institute of Infection, Veterinary and Ecological Sciences, Faculty of Health and Life Sciences, University of Liverpool, Leahurst Campus, Chester High Road, Neston CH64 7TE, Wirral, UK 


\section{Introduction}

Anterior cruciate ligament (ACL) injuries are common with a median annual incidence of $0.03 \%$ per person overall and up to $3.7 \%$ in professional athletes [52]. Potential consequences of an ACL tear include further knee injury, posttraumatic osteoarthritis, and reduced quality of life [21]; therefore, prompt, accurate diagnosis is important to expedite treatment and mitigate these risks.

ACL tears are diagnosed by combining patient history and physical examination with imaging modalities utilised if required [21]. History elements include a traumatic pivoting mechanism, typically without direct contact to the knee, a 'popping' or 'snapping' sensation, effusion within $2 \mathrm{~h}$ of injury and knee instability [13, 15, 25, 37, 75, 76]. Based on an overview of systematic reviews investigating the diagnostic validity of physical examination tests, the Lachman test is considered to be of high diagnostic value to confirm and exclude an ACL tear, while the pivot shift test may be used to rule in an ACL injury when positive [14]. The Lever sign demonstrates similar diagnostic accuracy to more established tests $[2,59]$, but these tests have not been compared directly using the same inclusion and exclusion criteria.

Although this synthesis of data represents the best available evidence to guide clinical practice [21], numerous studies in the aforementioned systematic reviews include subjects with additional knee ligament injury $[4,7,28,34$, $47,50,77]$, which could affect test sensitivity. Since up to half of all patients with an ACL tear sustain a concomitant medial or lateral ligament injury $[1,55,63]$, it is important to determine the diagnostic accuracy of ACL tests in the absence of such injury. Furthermore, previous meta-analyses have evaluated studies by methods that do not account for the non-independence of sensitivity and specificity, which are often negatively correlated. More recently, approaches such as bivariate random effects models have been recommended for meta-analysis of diagnostic test accuracy [27, $60]$.

The purpose of this systematic review with meta-analysis was to provide an updated synthesis of studies reporting the diagnostic accuracy of clinical tests for ACL tears (partial and complete) without concomitant knee ligament injury. Data are presented for the anterior drawer, Lachman, Lever sign and pivot shift tests [24, 42, 46, 73] performed without anaesthesia, in acute and post-acute presentations.

The study hypotheses were that ACL clinical tests will have lower sensitivity in the absence of concomitant ligament injury, and the diagnostic accuracy of the Lachman test will be superior to the Lever sign. The findings from this study will provide more accurate estimates of the diagnostic ability of ACL tests, to inform clinicians in these common clinical situations.

\section{Materials and methods}

The study was registered on PROSPERO (CRD42021231446). A Preferred Reporting Items for Systematic Review and Meta-Analyses (PRISMA) protocol [51] defined the aim, objectives, the 'Population, Intervention, Comparison, Outcomes and Study design' (PICOS) [3] framework, search terms, inclusion and exclusion criteria.

\section{Search strategy}

A search was conducted for relevant studies without restriction on date of publication using the bibliographic databases PubMed, Scopus, MEDLINE and Web of Science (Supplemental Table 1).

\section{Study selection}

Results from bibliographic databases were combined and duplicates removed. Studies obtained through screening previous systematic reviews were also considered and PRISMA flow diagram and checklist followed to screen literature and report selection of relevant studies (Fig. 1 and Supplemental Fig. 1) [51].

\section{Identification of eligible studies}

Inclusion and exclusion criteria for the study are defined in Supplemental Table 2. Bibliographic database search results were uploaded into Rayyan QCRI web application (https:// rayyan.qcri.org/cite) [56] and the titles and abstracts of every citation screened to exclude clearly irrelevant studies. Remaining citations were independently reviewed by PAS, RAO and RN for eligibility based on title, abstract and full text and conflicts resolved by consensus.

\section{Quality assessment}

Standardised assessment of the quality of reporting by primary diagnostic accuracy studies and risk of bias regarding applicability of results was determined using QUADAS-2 tool [78] (Supplemental Table 3).

\section{Data abstraction}

Values of $2 \times 2$ contingency tables [number of true positives (TP), false positives (FP), true negatives (TN) and false negatives $(\mathrm{FN})]$ were extracted from each study. If this information was not provided, the values were calculated from descriptive statistics presented within the study. If this was not possible for at least one of the two diagnostic properties of sensitivity $[\mathrm{TP} /(\mathrm{TP}+\mathrm{FN})]$ or specificity $[\mathrm{TN} /$ 
Fig. 1 PRISMA flow diagram showing selection process outcome. Retrieved studies were systematically excluded against the inclusion and exclusion criteria. Arrows pointing downwards indicate the process of identifying relevant articles. Arrows pointing to the right show articles excluded from the review
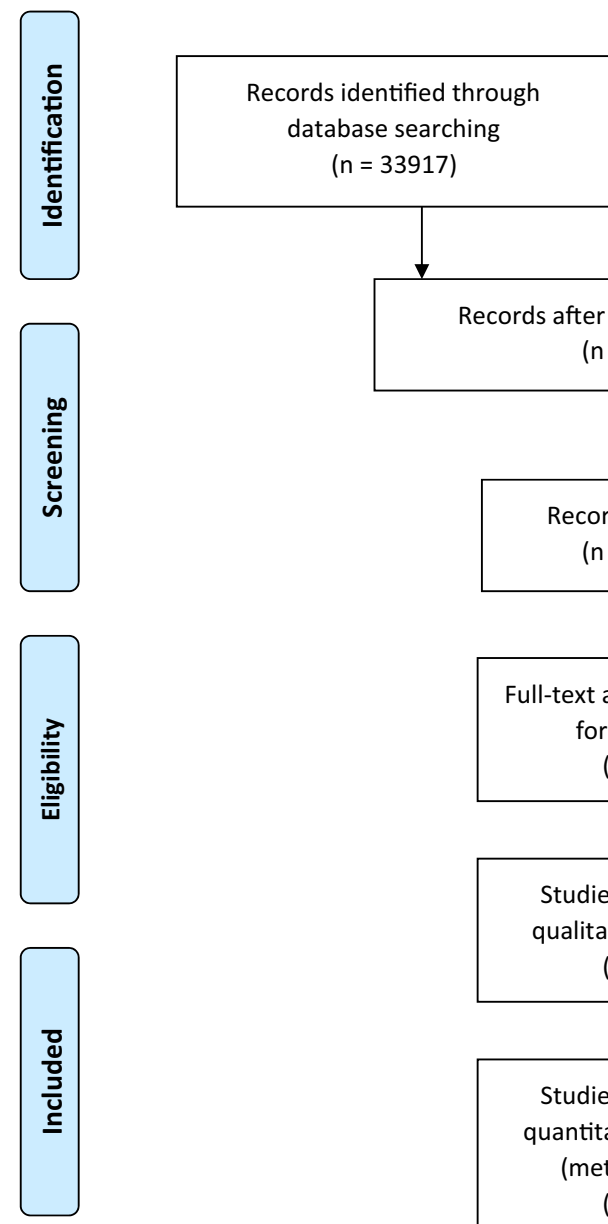

$$
(n=33917)
$$

Additional records identified through other sources $(n=24)$

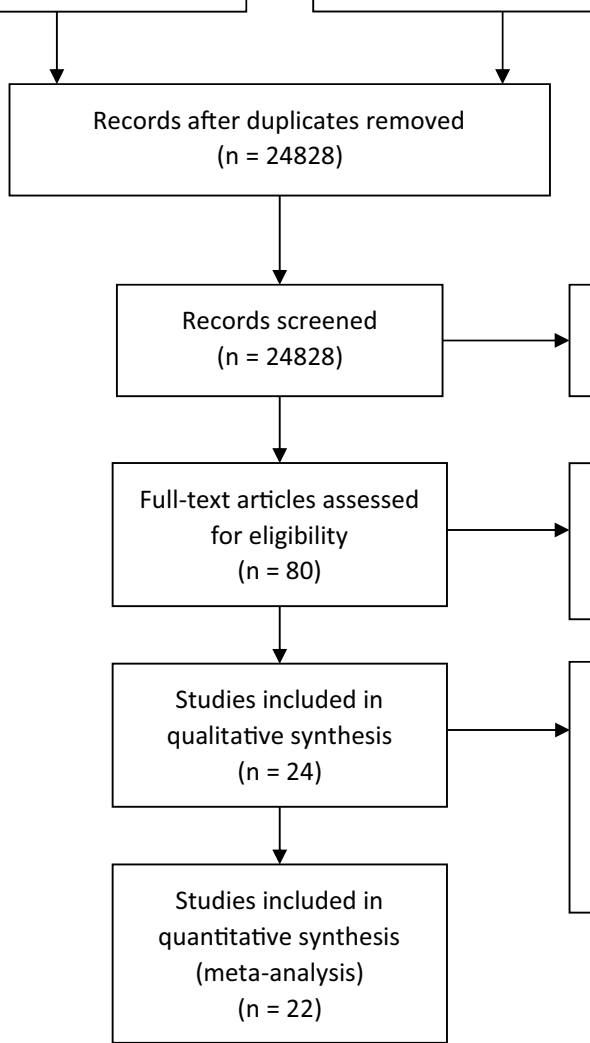

Records excluded

$(n=24748)$

Studies excluded from meta-analysis for failure to report sufficient information to reproduce a $2 \times 2$ contingency table $(n=2)$

$(\mathrm{TN}+\mathrm{FP})]$ the studies were excluded from meta-analysis. A cut-off of 3-weeks post-injury was used to differentiate acute ( $<3$ weeks) and post-acute $(>3$ weeks) presentations.

\section{Data analysis}

Bivariate diagnostic random-effects meta-analysis was performed where studies reported both sensitivity and specificity as this approach is considered more valid than univariate analysis $[19,65]$. A univariate random effects model metaanalysis was used where studies reported only sensitivity or specificity and to enable meaningful comparison with previous systematic reviews [65]. The sensitivity and specificity were analysed by subgroups of the time since injury (acute or post-acute), injury type (partial or complete tear) and reference used (arthroscopy or MRI). Positive (LR +) and negative (LR-) likelihood ratios were calculated from the values of sensitivity and specificity to determine the preto post-test shift in probability of an ACL tear [48]. The analysis was performed in R Studio (https://rstudio.com; supplemental information) [61] using mada [19] and meta [65] packages.

\section{Results}

\section{Selection of studies}

The total number of citations retrieved from the bibliographic databases was: PubMed 7369, Scopus 17125, MEDLINE 5094 and Web of Science 4329. Screening of previous systematic reviews identified 24 additional citations. Screening titles and abstracts of the citations against the inclusion and exclusion criteria identified 80 studies for potential inclusion with in-depth scrutiny of each article generating 24 studies for final inclusion in this review $[6,8,9,11,12$, $18,20,22,25,26,33,38,39,41-45,49,54,57,62,72$, 75]. Selection of studies is summarised in the PRISMA flow diagram (Fig. 1) and details of excluded studies with justifications provided in supplemental information.

\section{Study characteristics}

Comprehensive description of each study and patient cohorts is provided in Tables 1 and 2. Only two studies $[6,8]$ were not considered at risk of bias (Table 3). One study was an RCT [6], seven studies had a prospective design [8, 42, 43, 


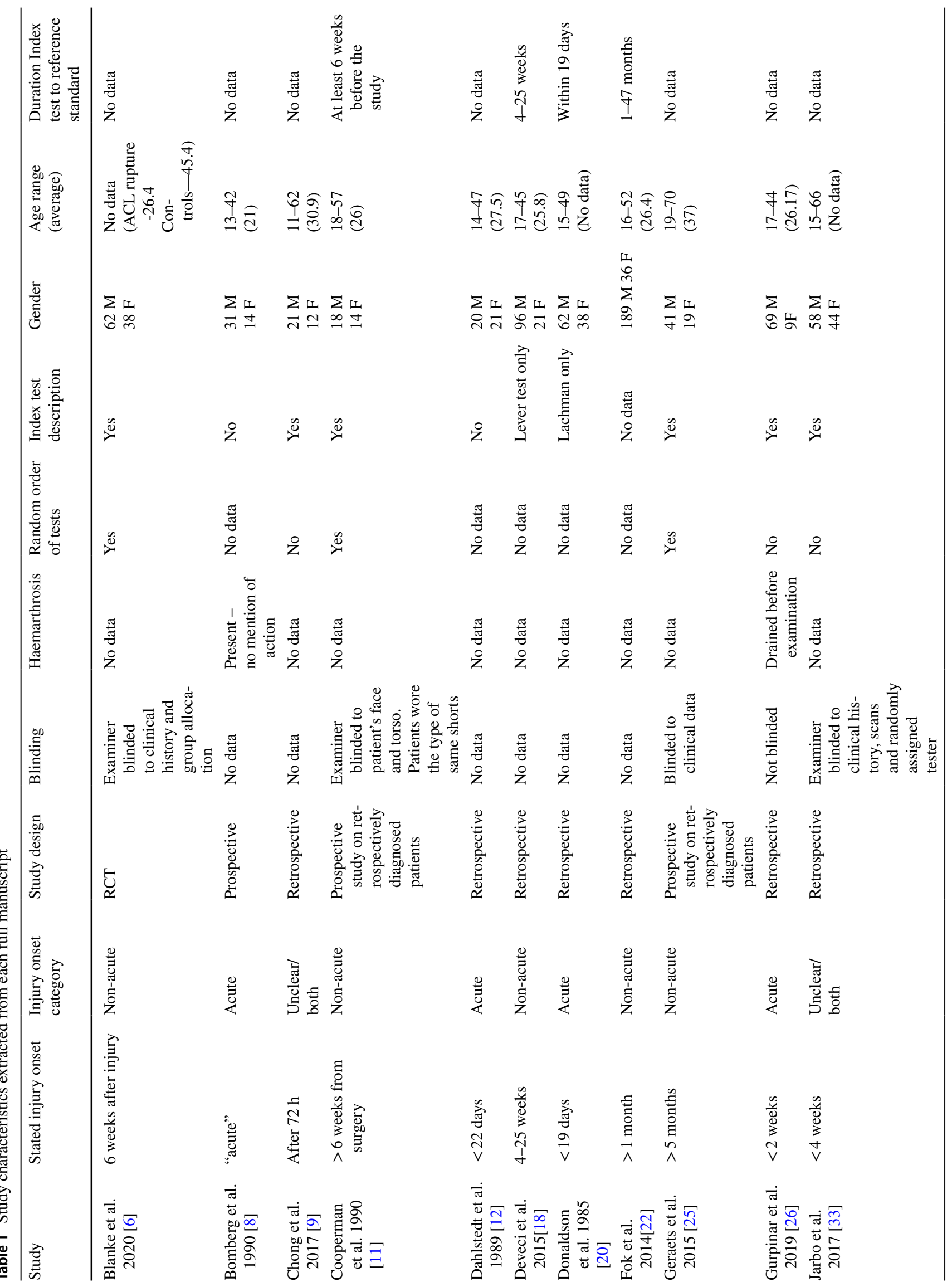




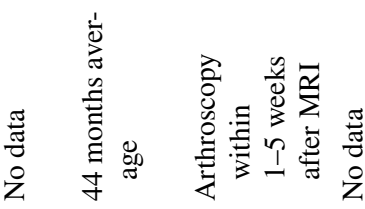

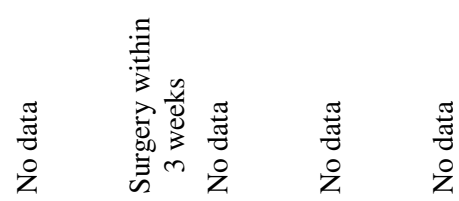

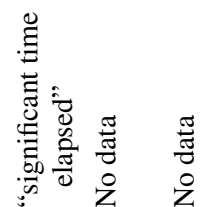

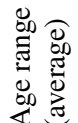

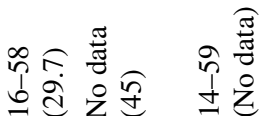
氶 子

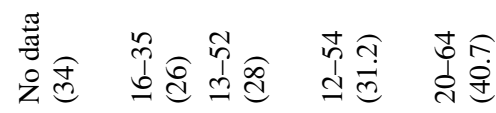

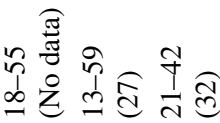

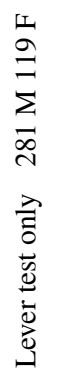

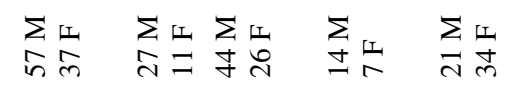

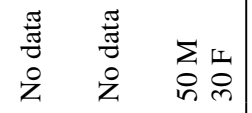

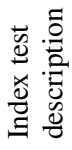

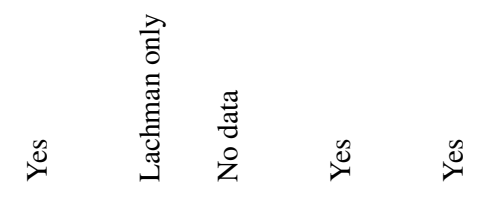

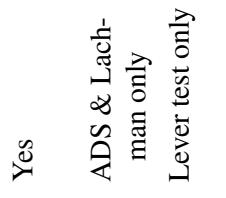
密

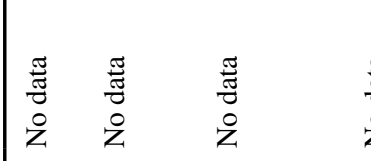

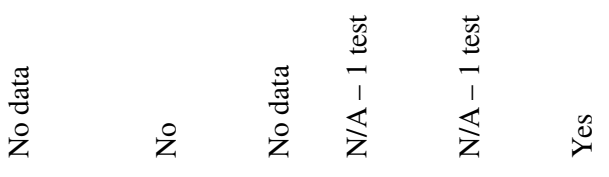

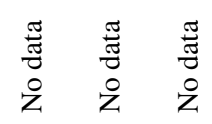

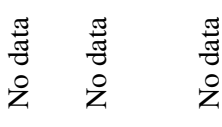

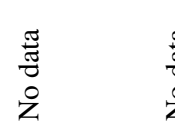

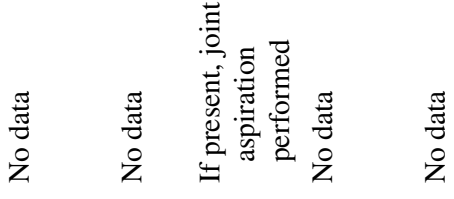

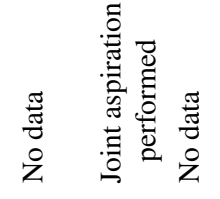

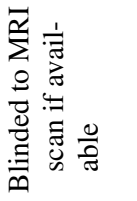

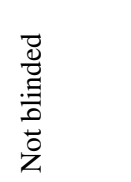

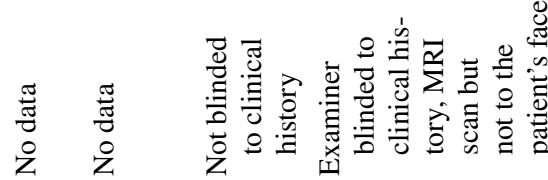

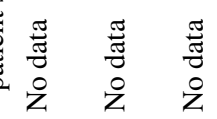

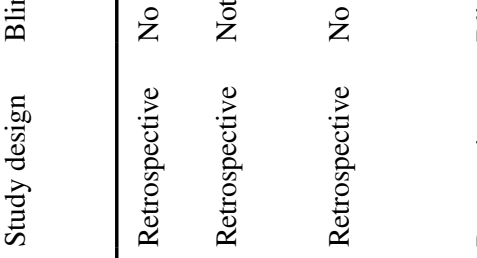

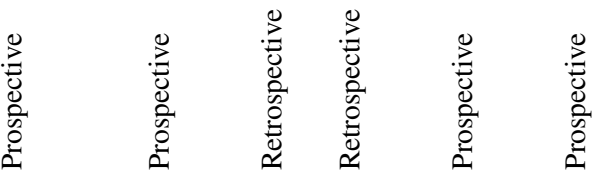

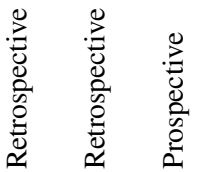

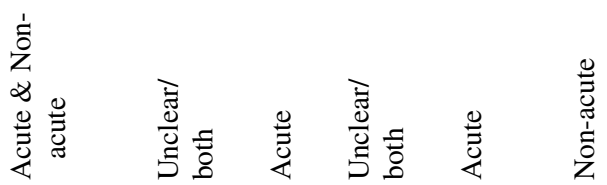

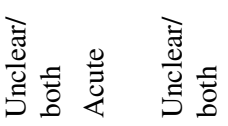

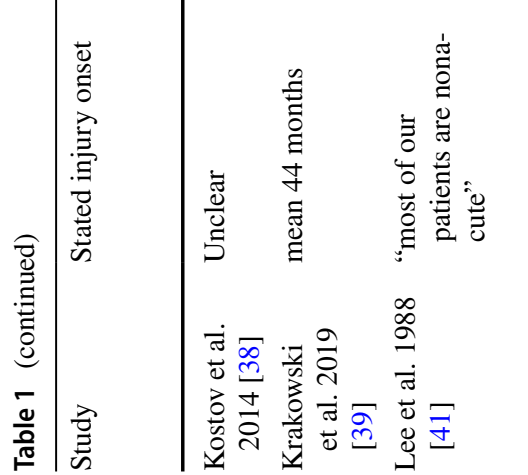

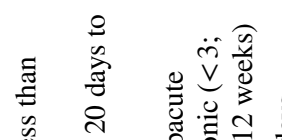

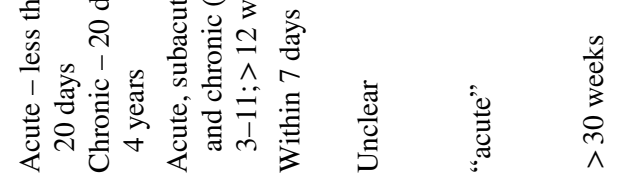

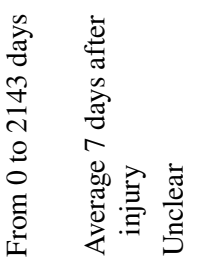

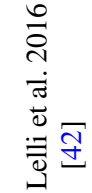

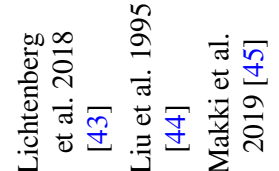

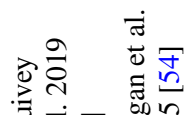
त)

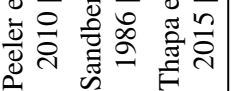


$49,54,72,75]$ and 14 assessed patients retrospectively [9, $12,18,20,22,26,33,38,39,41,44,45,57,62]$. Arthroscopy and/or arthrotomy was used as a gold standard in 17 studies $[6,8,9,11,12,18,20,22,25,38,39,43,44,54,57$, $62,72]$ with MRI reported as a reference standard in seven studies [26, 38, 41, 42, 45, 49, 75]. Isolated ACL tears were analysed in seven studies [6, 9, 11, 20, 25, 42, 49], whereas ten studies recruited patients with an isolated ACL tear or combined ACL tear and meniscal injury $[8,18,20,22,26$, $39,41,62,72,75]$. The spectrum of conditions was not specified or unclear in eight studies [12, 18, 33, 38, 43-45, 57]. Patient cohorts with complete ACL tears only were analysed by ten studies $[6,8,11,12,20,25,39,42,44,75]$, partial ACL tears only were analysed in two studies [22, 42], combined complete and partial ACL tears in nine studies $[9,18$, $22,26,38,43,45,49,75]$. Six studies did not specify the type of ACL tear $[33,41,54,57,62,72]$. The number of patients in cohorts extracted from studies ranged from six [22] to 217 [22]. The average age of patients ranged from 21 [8] to $45[6,39]$ with seven studies including patients below 16 years of age $[8,9,20,33,45,49,62]$. Time from injury was not defined in three studies [38, 45, 72] while acute, subacute and/or chronic injuries were included in the same cohort in six studies [9, 33, 41, 43, 57, 75]; three studies described patients as acute yet did not specify time from injury $[8,49]$ or provided only the average time [62].Each study has been screened for risk of bias based on 4 criteria of patient selection, index test, reference standard and flow and timing. Bias screening is presented as Low Risk (if the answer is "yes" to all signalling questions for a domain) High Risk (if the answer is "no" to all signalling questions for a domain), ? Unclear Risk (insufficient data reported precludes judgement)

Two studies performed arthrocentesis before examination $[26,62]$ and two studies did not aspirate the joint, while the remaining studies make no mention of such interventions. Six studies implemented measures to blind the examiner to patient history $[6,11,25,33,54,75]$ and available imaging $[6,11,25,33,42,54,75]$ or to prevent facial recognition of a previously seen patient [11], whilst other studies did not report and/or did not use such strategies. Random order of testing was applied in four studies $[6,11,25,54]$.

\section{Meta-analysis}

Bivariate random effects model meta-analysis was possible for data from 12 studies (Table 4 and Supplemental Tables 4, $5,6)[6,11,25,26,33,38,41,45,49,54,72,75]$. For all studies combined, the pivot shift test had the highest specificity (94\%) and LR + (10.70), producing a large shift in the positive post-test probability. However, this test also had the lowest sensitivity $(55 \%)$ and highest LR- (0.48), producing the smallest shift in negative post-test probability. The 


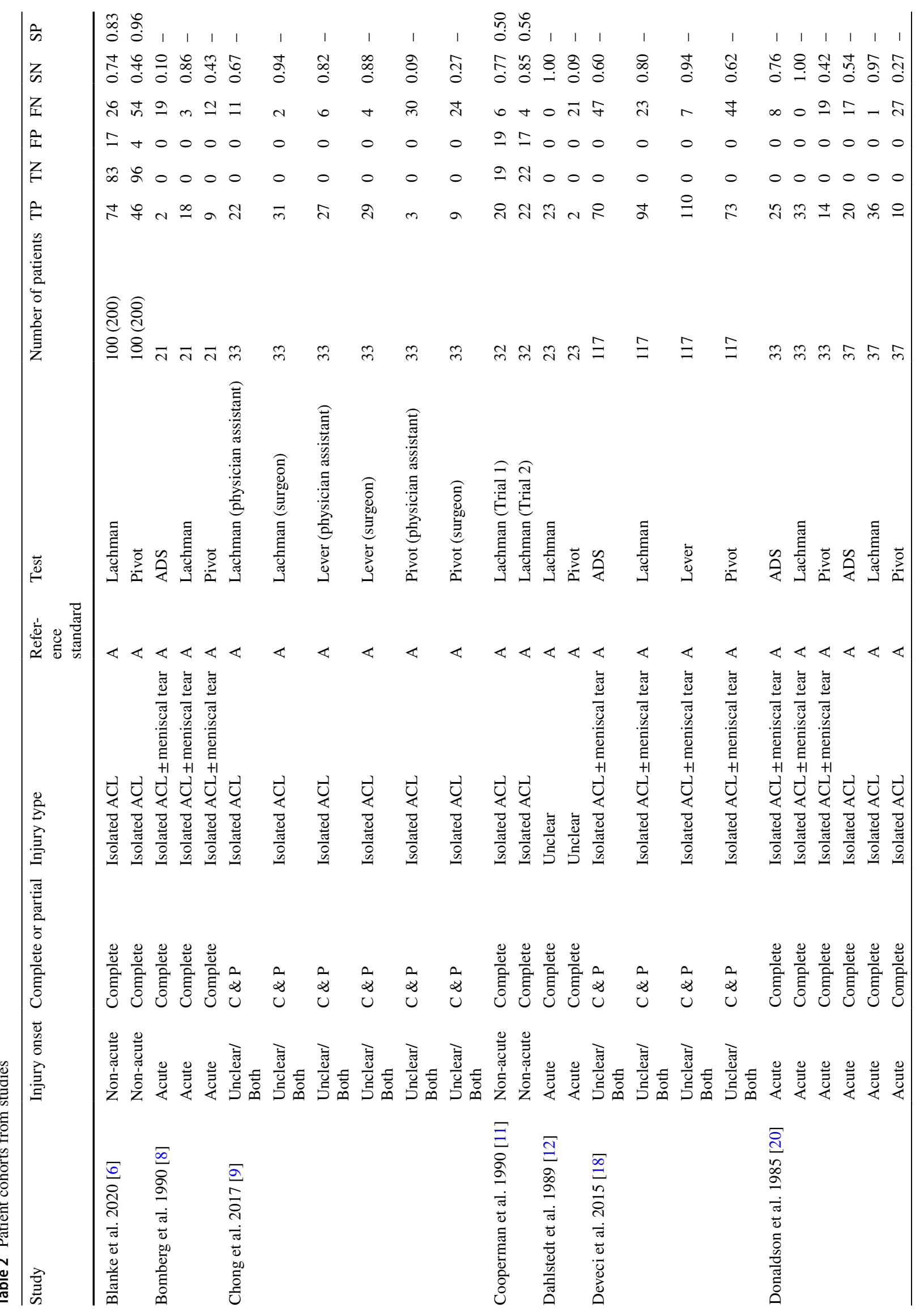




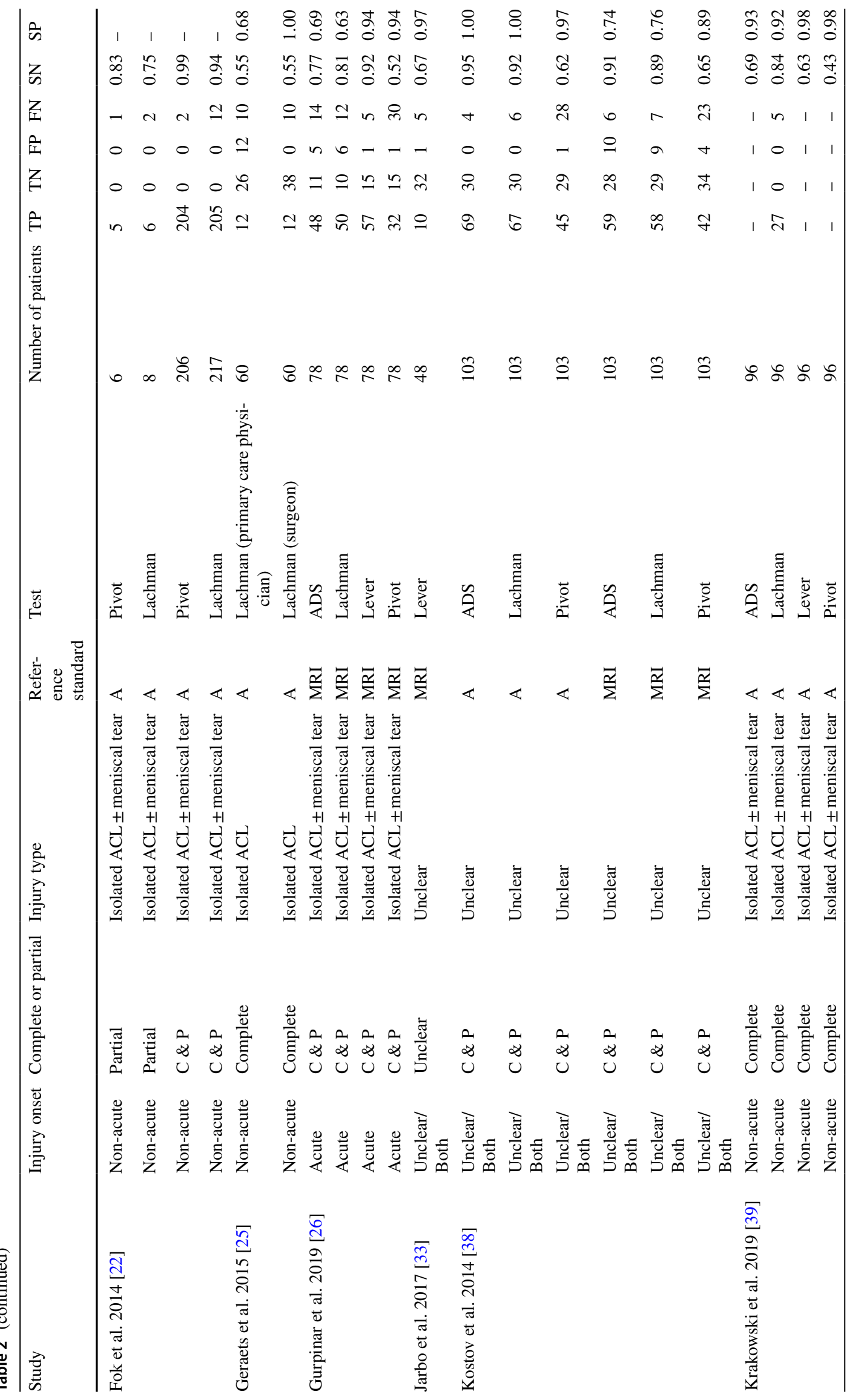




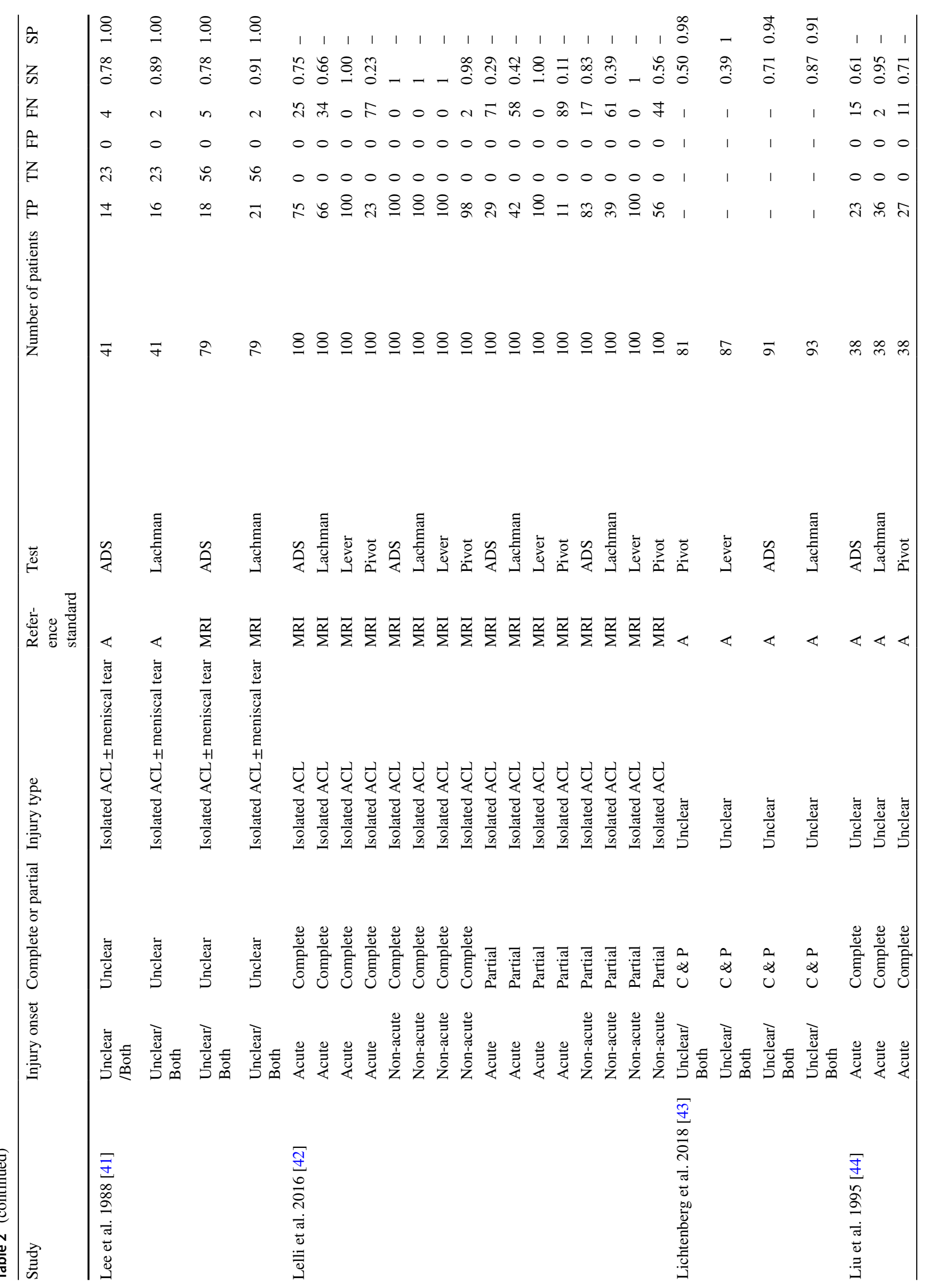




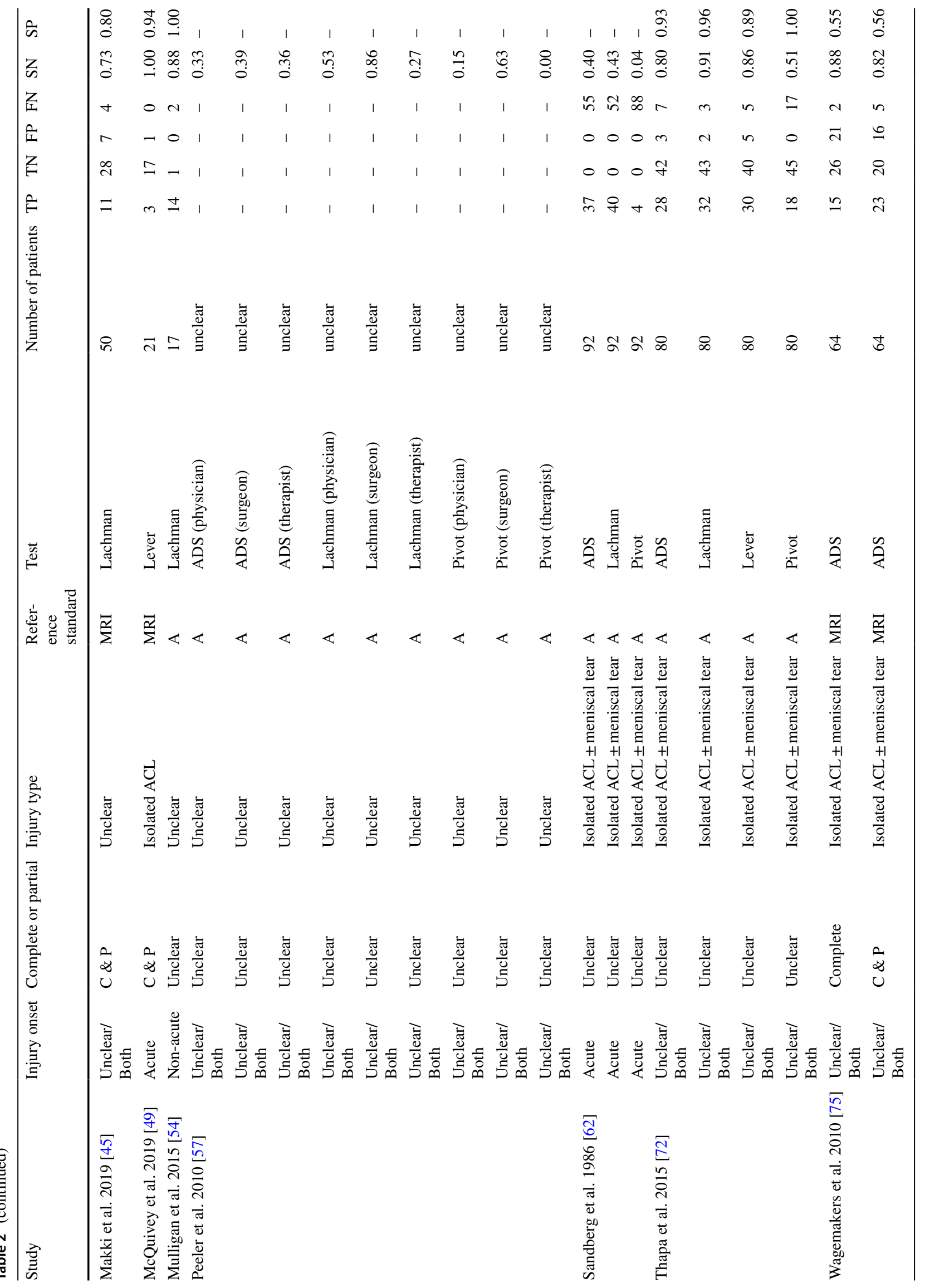


Lever sign produced moderate shifts in the positive posttest probability and was the only test to produce a moderate shift in the negative post-test probability. The anterior drawer and Lachman tests produced moderate shifts in the positive post-test probability and small shifts in the negative post-test probability. The post-test probability of an ACL tear for all tests is illustrated in Fig. 2 using a 36\% pre-test probability [63].

Based on studies using gold-standard arthroscopy and/or arthrotomy for reference $[6,8,9,11,12,18,20,22,25,38$, $39,43,44,54,57,62,72]$, the anterior drawer was the most accurate test with the highest $\mathrm{LR}+(25.10)$ and joint lowest LR - (0.17) alongside the Lever sign, but LR+confidence intervals were wide. The pivot shift test produced large shifts in the positive post-test probability, with the Lachman and Lever sign producing moderate shifts. The anterior drawer and Lever sign tests produced moderate shifts in the negative post-test probability, with the Lachman and pivot shift tests producing small shifts.

Where MRI was used as the reference standard (Supplemental Table 4) [26, 38, 41, 42, 45, 49, 75], the Lever sign was the most accurate test with the highest $\mathrm{LR}+(13.50)$ and lowest LR- (0.20). The specificity and LR + of the anterior drawer and LR + of the pivot shift were considerably lower than values reported using arthroscopy and/or arthrotomy.

For specific presentations, bivariate random effects model meta-analysis was only possible for the Lachman test in post-acute injuries and complete ACL tears. In both presentations, the Lachman test produced small shifts in the positive and negative post-test probability (Supplemental Tables 5 and 6).

Pooled diagnostic accuracy estimates were determined with univariate analyses of data from 23 studies [6, 8, 9, 11, $12,18,20,22,25,26,33,38,39,41-45,49,54,57,72,75]$ (Table 4 and Supplemental Tables 4, 5, 6). In acute presentations ( $<3$ weeks since injury), the Lever sign was the most accurate test with the highest sensitivity (100\%) and joint highest specificity (94\%) alongside the pivot shift. In postacute presentations ( $>3$ weeks since injury), the Lever sign had the highest sensitivity (100\%), with the anterior drawer and pivot shift tests demonstrating considerably higher sensitivity values than in acute presentations. The Lachman test's specificity was also higher than in acute presentations; insufficient data were available to calculate specificity values for the anterior drawer or Lever sign tests.

For studies reporting complete ACL tears only (Supplemental Table 5), the pivot shift test demonstrated the highest specificity (96\%) but lowest sensitivity (48\%). The Lever sign and Lachman tests had the highest sensitivity, with Lachman also demonstrating high specificity; insufficient data were available to determine the Lever sign test's specificity in complete tears. For partial ACL tears, sensitivity values only were available for all four tests (Supplemental 
Table 3 QUADAS-2 tool assessment shows potential risks based on study's design

\begin{tabular}{|c|c|c|c|c|c|c|c|}
\hline & & & BIAS & & & CABILITY CON & \\
\hline & $\begin{array}{l}\text { PATIENT } \\
\text { SELECTION }\end{array}$ & $\begin{array}{l}\text { INDEX } \\
\text { TEST }\end{array}$ & $\begin{array}{l}\text { REFERENCE } \\
\text { STANDARD }\end{array}$ & $\begin{array}{l}\text { FLOW AND } \\
\text { TIMING }\end{array}$ & $\begin{array}{l}\text { PATIENT } \\
\text { SELECTION }\end{array}$ & INDEX TEST & $\begin{array}{l}\text { REFERENCE } \\
\text { STANDARD }\end{array}$ \\
\hline Blanke et al. $2020^{(6)}$ & (:) & (;) & (;) & (;) & (;) & (;) & (;) \\
\hline Bomberg et al. $1990^{(8)}$ & (:) & (;) & ;) & $?$ & (:) & ;) & (:) \\
\hline Chong et al. $2017^{(9)}$ & (:) & (:) & (;) & (:) & (2) & (;) & (;) \\
\hline Cooperman et al. $1990^{(11)}$ & (2) & (2) & (;) & (:) & (2) & (2) & (:) \\
\hline Dahlstedt et al. $1989^{(12)}$ & ;:) & (2) & (;) & (;) & :) & (:) & (:) \\
\hline Deveci et al. $2015^{(18)}$ & (2) & ? & (;) & (:) & (2) & (;) & (;) \\
\hline Donaldson et al. $1985^{(20)}$ & (2) & (;) & (:) & (:) & (2) & (;) & ;) \\
\hline Fok et al. $2014^{(22)}$ & (2) & (2) & (:) & (:) & (:) & (2) & (;) \\
\hline Geraets et al. $2015^{(25)}$ & (:) & (:) & (;) & (:) & (2) & (;) & (;) \\
\hline Gurpinar et al. 2019 & (2) & (:) & (2) & (:) & : : & ;) & (;) \\
\hline Jarbo et al. $2017^{(33)}$ & (2) & (2) & (2) & (;) & (2) & (2) & (;) \\
\hline Kostov et al. $2014^{(38)}$ & (:) & (2) & (;) & $?$ & ;) & (:) & (;) \\
\hline Krakowski et al. $2019^{(39)}$ & (2) & (:) & (:) & $?$ & (2) & (:) & (;) \\
\hline Lee et al. $1988^{(41)}$ & (2) & (;) & (;) & $?$ & (2) & (;) & (;) \\
\hline Lelli et al. $2016^{(42)}$ & (2) & (:) & (2) & $?$ & (2) & (;) & (:) \\
\hline Lichtenberg et al. $2018^{(43)}$ & ;: & $?$ & (;) & ? & : $:$ & (;) & (:) \\
\hline Liu et al. $1995^{(44)}$ & (2) & (;) & (;) & (;) & (2) & (;) & (;) \\
\hline Makki et al. $2019^{(45)}$ & (2) & (:) & (2) & (:) & : & (:) & ;) \\
\hline McQuivey et al. 2019 $9^{(49)}$ & (2) & (2) & (2) & $?$ & (2) & (2) & (:) \\
\hline Mulligan et al. $2015^{(54)}$ & (2) & (;) & (;) & $?$ & (2) & (:) & (;) \\
\hline Peeler et al. $2010^{(57)}$ & (2) & (:) & (:) & (2) & (2) & (:) & (:) \\
\hline Sandberg et al. $1986^{(62)}$ & (:) & (:) & (;) & $?$ & (:) & (;) & (;) \\
\hline Thapa et al. $2015^{(72)}$ & (;) & (2) & (;) & $?$ & (;) & (2) & (;) \\
\hline Wagemakers et al. $2010^{(75)}$ & (:) & (:) & (2) & (:) & ;) & ;) & (:) \\
\hline
\end{tabular}

Each study has been screened for risk of bias based on 4 criteria of patient selection, index test, reference standard and flow and timing. Bias screening is presented as (-)Low Risk (if the answer is "yes" to all signalling questions for a domain) :-High Risk (if the answer is "no" to all signalling questions for a domain), ? Unclear Risk (insufficient data reported precludes judgement).

Table 4 Univariate and bivariate analysis of diagnostic clinical tests for all studies evaluated

\begin{tabular}{|c|c|c|c|c|c|}
\hline & \multicolumn{5}{|c|}{ All studies $[95 \% \mathrm{CI}]$} \\
\hline & Sn & $\mathrm{Sp}$ & $\mathrm{LR}+$ & LR- & AUC \\
\hline Anterior Drawer (UA) & $\begin{array}{l}0.75 \\
{[0.61 ; 0.86]}\end{array}$ & $\begin{array}{l}0.92 \\
{[0.67 ; 0.99]}\end{array}$ & $\begin{array}{l}2.4 \\
{[1.58 ; 3.64]}\end{array}$ & $\begin{array}{l}0.28 \\
{[0.20 ; 0.42]}\end{array}$ & - \\
\hline Anterior Drawer (BA) & $\begin{array}{l}0.83 \\
{[0.77 ; 0.88]}\end{array}$ & $\begin{array}{l}0.85 \\
{[0.64 ; 0.95]}\end{array}$ & $\begin{array}{l}6.34 \\
{[2.32 ; 15.30]}\end{array}$ & $\begin{array}{l}0.20 \\
{[0.14 ; 0.30]}\end{array}$ & 0.87 \\
\hline Lachman (UA) & $\begin{array}{l}0.85 \\
{[0.77 ; 0.91]}\end{array}$ & $\begin{array}{l}0.93 \\
{[0.77 ; 0.98]}\end{array}$ & $\begin{array}{l}2.72 \\
{[1.97 ; 3.77]}\end{array}$ & $\begin{array}{l}0.27 \\
{[0.20 ; 0.36]}\end{array}$ & - \\
\hline Lachman (BA) & $\begin{array}{l}0.81 \\
{[0.73 ; 0.87]}\end{array}$ & $\begin{array}{l}0.85 \\
{[0.73 ; 0.92]}\end{array}$ & $\begin{array}{l}5.72 \\
{[2.82 ; 10.80]}\end{array}$ & $\begin{array}{l}0.24 \\
{[0.15 ; 0.35]}\end{array}$ & 0.882 \\
\hline Lever Sign (UA) & $\begin{array}{l}0.98 \\
{[0.88 ; 1.00]}\end{array}$ & $0.93[086 ; 0.96]$ & $\begin{array}{l}4.56 \\
{[2.79 ; 7.45]}\end{array}$ & $\begin{array}{l}0.15 \\
{[0.09 ; 0.26]}\end{array}$ & - \\
\hline Lever Sign (BA) & $\begin{array}{l}0.83 \\
{[0.68 ; 0.92]}\end{array}$ & $\begin{array}{l}0.91 \\
{[0.83 ; 0.95]}\end{array}$ & $9.66[5.01 ; 17.30]$ & $\begin{array}{l}0.18 \\
{[0.09 ; 0.34]}\end{array}$ & 0.938 \\
\hline Pivot Shift (UA) & $\begin{array}{l}0.48 \\
{[0.29 ; 0.68]}\end{array}$ & $\begin{array}{l}0.96 \\
{[0.92 ; 0.98]}\end{array}$ & $\begin{array}{l}1.45 \\
{[0.73 ; 2.87]}\end{array}$ & $\begin{array}{l}0.52 \\
{[0.43 ; 0.64]}\end{array}$ & - \\
\hline Pivot Shift (BA) & $\begin{array}{l}0.55 \\
{[0.47 ; 0.62]}\end{array}$ & $\begin{array}{l}0.94 \\
{[0.88 ; 0.97]}\end{array}$ & $\begin{array}{l}10.70 \\
{[5.43 ; 19.30]}\end{array}$ & $\begin{array}{l}0.48 \\
{[0.40 ; 0.56]}\end{array}$ & 0.828 \\
\hline
\end{tabular}

$A U C$ area under the curve, $B A$ bivariate analysis, $C I$ confidence interval, $L R-$ negative likelihood ratio, $L R+$ positive likelihood ratio, $S n$ sensitivity, $S p$ specificity, $U A$ univariate analysis

Comparison of diagnostic clinical tests (anterior drawer, Lachman, Lever sign and pivot shift) in complete and partial ACL tears, acute and post-acute clinical presentations with arthroscopy and MRI as the reference standard was performed using univariate and bivariate modelling 


\section{A) Anterior Drawer}

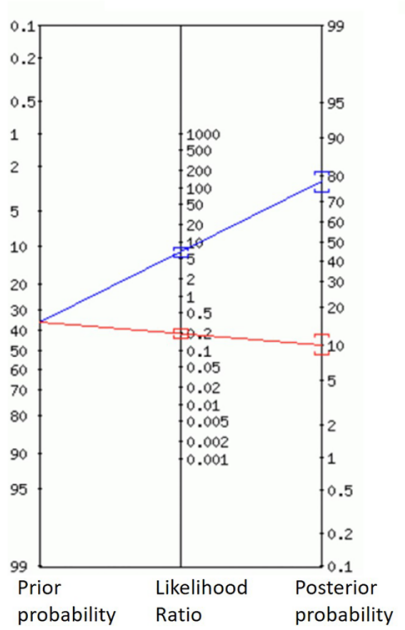

B) Lachman

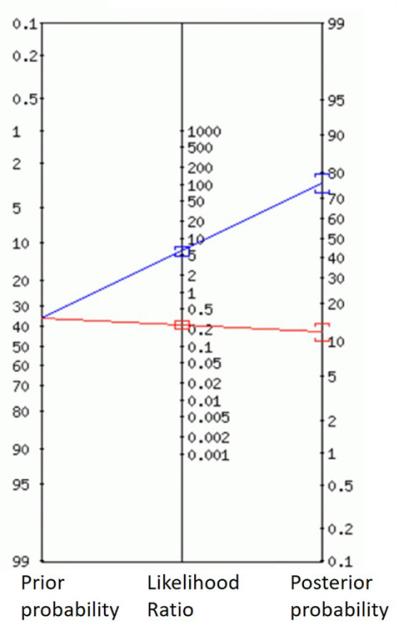

C) Lever Sign

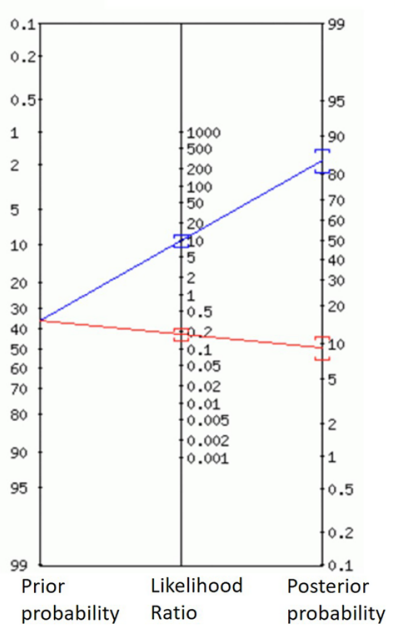

D) Pivot Shift

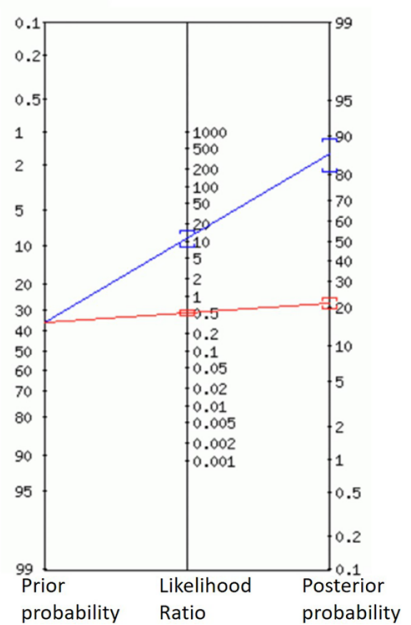

Fig. 2 Fagan's nomogram of shift in pre-test to post-test probability of clinical tests. Fagan's nomograms illustrating the shift in pre-test to post-test probability for the a anterior drawer, $\mathbf{b}$ Lachman, $\mathbf{c}$ Lever sign and $\mathbf{d}$ Pivot shift tests. The pre-test probability of acute ACL tear is shown on the left vertical axis (36\%). The post-test probability is

Table 5). With exception of the Lever sign, all tests demonstrated inferior diagnostic ability for ruling out partial ACL tears compared with complete ruptures.

\section{Discussion}

The most important finding of the present study was the lower diagnostic accuracy values for the Lachman test compared with those reported in previous systematic reviews $[5,40,74]$. Based on a bivariate analysis of all studies combined, the pivot shift and Lever sign were the best tests overall for ruling in or ruling out an ACL tear, respectively. The diagnostic accuracy values between the anterior drawer, Lachman and Lever sign tests were comparable, but the Lachman test demonstrated lower accuracy in post-acute presentations and complete ACL tears alone. However, results should be interpreted with caution due to limited quality evidence and heterogeneity of included studies.

To date, ten previous systematic reviews have been conducted to determine the diagnostic accuracy of clinical tests for ACL injury [2, 5, 29, 31, 40, 59, 64, 67, 70, 74]. Eight reviews compared the anterior drawer, Lachman, and pivot shift tests [5, 29, 31, 40, 64, 67, 70, 74], with the remaining two reviews reporting on the Lever sign test alone [2, 59]. The highest quality meta-analyses for pertinent tests utilised univariate approaches $[2,5,59]$, while the only meta-analysis employing a bivariate method [64] reported diagnostic estimates for the anterior drawer and Lachman tests alone without corresponding likelihood ratios [64], shown on the right vertical axis. The middle vertical axis shows value of likelihood ratio. The blue line represents a change in ACL tear probability when the test is positive. The red line indicates a change in ACL injury probability when test is negative

limiting comparison between studies. The current systematic review with meta-analysis is therefore the first to provide pooled diagnostic estimates using bivariate random effects models for the pivot shift and Lever sign tests overall, and the Lachman test in specific presentations. This study is also the first to compare all four tests directly using the same criteria, report the diagnostic accuracy of the Lever sign test in acute and post-acute presentations, and includes several new studies.

With exception of Leblanc et al. [40], which excluded studies published before the year 2000, previous systematic reviews included subjects with concomitant knee ligament injury [4, 7, 28, 34, 47, 50, 77]. In an ACL deficient knee, concomitant medial or lateral knee injuries can decrease or increase the grading of the pivot shift test respectively $[69,71]$ or preclude the pivot shift phenomenon from taking place altogether [32]. Likewise, the anterior drawer and Lachman tests are thought to become increasingly positive if secondary restraints to anterior tibial translation are also injured $[5,30,35]$. No studies have validated the pathomechanics of the Lever sign [33], therefore it is unknown whether additional ligament injury influences the outcome of this test. Since concomitant ligament injuries may affect the sensitivity of an ACL test, the current study provides valuable information regarding the diagnostic accuracy of ACL tests in the absence of such injuries. 


\section{Comparison with other studies}

Benjaminse et al. [5], the highest quality meta-analysis with the most studies included [14], employed a univariate approach and describe Lachman as the most valid test overall (Sn:85\%, Sp:94\%). An equivalent univariate analysis performed in the current study demonstrates almost identical values (Sn:85\%, Sp:93\%) (Table 4) but bivariate analysis, which provides a more accurate estimate of pooled effect sizes, indicates lower diagnostic accuracy. Since Benjaminse et al. [5] included studies with concomitant knee ligament injury and the current review excluded such studies, concomitant ligament injury may not necessarily affect the validity of the Lachman test, but its diagnostic accuracy may have been previously overestimated. Future studies should directly compare the diagnostic accuracy of tests in ACLinjured patients with and without additional ligament injury.

The findings of the present study support recommendations that the pivot shift should be used to rule in an ACL tear when positive $[5,14]$ but the Lachman test did not demonstrate superior validity when compared with the anterior drawer or Lever sign; therefore, the hypotheses were rejected. Specifically, the diagnostic accuracy of the Lachman test is considerably lower than previously reported in post-acute presentations [5] and complete tears [40] based on bivariate analysis values.

\section{Lever sign caution}

The lever sign appears to be an accurate test regardless of time since injury or tear type, somewhat refuting the interdependence between sensitivity and specificity. However, it is worth noting that the only study with moderate methodology reported a sensitivity of 68\% [33] and most studies demonstrate limited quality [2, 59]. Reiman et al. [59] reported two diagnostic accuracy values, one including and the other excluding data from the original study [42]. With the original data omitted (400 tests with no false positive or false negative results), the LR + decreased from 128.0 to 13.1 indicating verification and case-control bias [59]. Other studies reporting on the Lever sign test are also at risk of verification bias $[9,18,26,33,39,43,49,72]$; therefore, results based on time since injury and tear type should be interpreted with caution.

The original Lever sign study data [42] were included in univariate analyses but excluded from bivariate analyses; the latter demonstrates inferior diagnostic values for the Lever sign test, yet it is still comparable with the other tests. Although bivariate analysis of MRI studies identifies the Lever sign as the most accurate test for diagnosing ACL tears, the diagnostic accuracy of MRI is dependent on magnetic field strength $[58,66]$ and arthroscopic assessment remains the gold standard; therefore, results should be interpreted accordingly. Given that the Lever sign is the only test to produce a moderate shift in the negative posttest probability, other modalities (i.e., arthrometry, MRI or arthroscopy) should be considered when the history is suggestive of an ACL injury, but clinical tests are negative.

\section{Strengths, limitations and recommendations}

To ensure this review was as clinically relevant as possible, only data for clinical tests performed on non-anaesthetised (awake) patients, without additional measuring equipment (e.g., arthrometry), were included. PRISMA guidelines and QUADAS-2 risk of bias analysis were used to promote methodological quality of the study. Where possible, a bivariate random effects model meta-analysis was performed as this method provides the most accurate estimate of pooled effect sizes and is recommended for meta-analysis of diagnostic test accuracy [27]. However, only 12 studies qualified for bivariate analysis and a lack of sufficient data precluded comparison between tests based on time since injury and tear type. Further research is required to establish more accurate estimates for the Lachman test in acute presentations and partial ACL tears using bivariate analysis.

Univariate analyses were performed where bivariate analysis was not possible and to allow comparison with previous systematic reviews $[2,5,59]$, but the difference between methods should be acknowledged. For example, univariate analyses in post-acute presentations and complete ACL tears demonstrate higher sensitivity and specificity values for the Lachman test than bivariate methods, thereby overestimating the test's diagnostic accuracy. The likelihood ratios calculated by univariate analysis also cast doubt on the accuracy and reliability of these values; therefore, results should be interpreted with caution.

The methodological quality of many studies was compromised by numerous factors including a retrospective design and lack of examiner blinding from clinical information that could bias the test outcome. With specific reference to the Lever sign test, studies should clearly report the landmarks chosen for hand placement, surface used (hard or soft), fist size, calf size and softness, all of which could affect test outcomes [33, 39, 42, 47]. Future studies should comply with the STARD guidelines [10] for completeness and transparency of reporting.

For this review, arbitrary time frames were used to differentiate acute and post-acute injuries. Whilst the terminology and time frames are a subject of debate, these categories were applied based on the most frequently reported thresholds amongst included studies. In addition to time since injury, future studies should report other covariables that could influence the outcome of a test. For example, a patient that is examined 4 weeks after injury may no longer be categorised as 'acute' but can still present with impairments that 
impact the examiner's ability to perform a test unequivocally (e.g., pain, effusion, protective guarding). It is proposed that presentations should be differentiated not only by the time since injury, but also the presence or absence of associated impairments. This has previously been suggested to improve patient care following injury [36].

Studies with concomitant ligament injury were excluded from this systematic review but those reporting non-obstructive meniscal tears were included. Meta-regression analysis demonstrated increased sensitivity of the Lachman test with a concomitant meniscal tear, but no difference for the pivot shift or Lever sign tests. No studies reported meniscal root tears or ramp lesions, which have been shown to increase anterior and rotational laxity in an ACL deficient knee [16, $17,23,53,68]$. However, the awareness and understanding of these associated lesions has improved over the last decade and they may, therefore, have been overlooked in older studies. Future studies should compare ACL test findings with and without concomitant meniscal injury, to determine their impact on diagnostic accuracy.

\section{Conclusion}

In the absence of concomitant knee ligament injury, the pivot shift and Lever sign tests demonstrate the highest diagnostic accuracy for ruling in or ruling out an ACL tear, respectively. The anterior drawer, Lachman and Lever sign tests demonstrate similar diagnostic accuracy, but diagnostic accuracy values for the Lachman test are lower than previously reported. Within the clinical setting, other modalities (including MRI and arthrometry) are recommended when the history is suggestive of an ACL tear, but tests are negative. Where tests are positive, clinicians can diagnose an ACL tear confidently without additional assessment techniques.

Supplementary Information The online version contains supplementary material available at https://doi.org/10.1007/s00167-022-06898-4.

Acknowledgements The authors wish to acknowledge the support of the University of Liverpool Clinical Sciences Masters in Research Programme.

Author contributions PAS, RN and RAO were involved in the formulation of research question, experimental design and scope of the study. PAS performed bibliographic database searches. Scrutiny of studies against inclusion and exclusion criteria was performed by PAS, RN and RAO. Acquisition, synthesis and meta-analysis of data was performed by PAS and TWM. PAS, RN, TWM and RAO were involved in the writing and revision of manuscript drafts, and approval of the final manuscript.

Funding It is funded by University of Liverpool Clinical Sciences Masters in Research Programme.

\section{Declarations}

Conflict of interest The authors declare no conflicts of interest.

Ethical approval The study did not require ethical approval for use of human participants or animals.

Informed consent The study did not involve human participants and requirement for informed consent.

Open Access This article is licensed under a Creative Commons Attribution 4.0 International License, which permits use, sharing, adaptation, distribution and reproduction in any medium or format, as long as you give appropriate credit to the original author(s) and the source, provide a link to the Creative Commons licence, and indicate if changes were made. The images or other third party material in this article are included in the article's Creative Commons licence, unless indicated otherwise in a credit line to the material. If material is not included in the article's Creative Commons licence and your intended use is not permitted by statutory regulation or exceeds the permitted use, you will need to obtain permission directly from the copyright holder. To view a copy of this licence, visit http://creativecommons.org/licenses/by/4.0/.

\section{References}

1. Abbasi D, May MM, Wall EJ et al (2012) MRI findings in adolescent patients with acute traumatic knee hemarthrosis. J Pediatr Orthop 32(8):760-764

2. Abruscato K, Browning K, Deleandro D et al (2019) Diagnostic accuracy of the Lever sign in detecting anterior cruciate ligament tears: a systematic review and meta-analysis. Int J Sports Phys Ther 14(1):2-13

3. Amir-Behghadami M, Janati A (2020) Population, Intervention, Comparison, Outcomes and Study (PICOS) design as a framework to formulate eligibility criteria in systematic reviews. Emerg Med J 37(6):387

4. Anderson AF, Lipscomb AB (1989) Preoperative instrumented testing of anterior and posterior knee laxity. Am J Sports Med 17(3):387-392

5. Benjaminse A, Gokeler A, van der Schans CP (2006) Clinical diagnosis of an anterior cruciate ligament rupture: a meta-analysis. J Orthop Sports Phys Ther 36(5):267-288

6. Blanke F, Haenle M, Feitenhansl A et al (2020) The forced active buckling sign: a new clinical test for the diagnosis of ACL insufficiency. J Knee Surg 33(1):42-47

7. Boeree NR, Ackroyd CE (1991) Assessment of the menisci and cruciate ligaments: an audit of clinical practice. Injury 22(4):291-294

8. Bomberg BC, McGinty JB (1990) Acute hemarthrosis of the knee: indications for diagnostic arthroscopy. Arthroscopy 6(3):221-225

9. Chong AC, Whitetree C, Priddy MC et al (2017) Evaluating different clinical diagnosis of anterior cruciate ligament ruptures in providers with different training backgrounds. Iowa Orthop J 37:71-79

10. Cohen JF, Korevaar DA, Altman DG et al (2016) STARD 2015 guidelines for reporting diagnostic accuracy studies: explanation and elaboration. BMJ Open 6(11):e012799

11. Cooperman JM, Riddle DL, Rothstein JM (1990) Reliability and validity of judgments of the integrity of the anterior cruciate ligament of the knee using the Lachman's test. Phys Ther 70(4):225-233 
12. Dahlstedt LJ, Dalén N (1989) Knee laxity in cruciate ligament injury. Value of examination under anesthesia. Acta Orthop Scand 60(2):181-184

13. Décary S, Fallaha M, Belzile S et al (2018) Clinical diagnosis of partial or complete anterior cruciate ligament tears using patients' history elements and physical examination tests. PLoS ONE 13(6): 0198797

14. Décary S, Ouellet P, Vendittoli PA et al (2017) Diagnostic validity of physical examination tests for common knee disorders: an overview of systematic reviews and meta-analysis. Phys Ther Sport 23:143-155

15. Della Villa F, Buckthorpe M, Grassi A et al (2020) Systematic video analysis of ACL injuries in professional male football (soccer): injury mechanisms, situational patterns and biomechanics study on 134 consecutive cases. Br J Sports Med 54(23):1423-1432

16. DePhillipo NN, Dornan GJ, Dekker TJ et al (2020) Clinical characteristics and outcomes after primary ACL reconstruction and meniscus ramp repair. Orthop J Sports Med 8(4):2325967120912427

17. DePhillipo NN, Moatshe G, Brady A et al (2018) Effect of meniscocapsular and meniscotibial lesions in ACL-deficient and ACLreconstructed knees: a biomechanical study. Am J Sports Med 46(10):2422-2431

18. Deveci A, Cankaya D, Yilmaz S et al (2015) The arthroscopical and radiological corelation of lever sign test for the diagnosis of anterior cruciate ligament rupture. Springerplus 4:830

19. Doebler P, Holling H (2015) Meta-analysis of diagnostic accuracy with mada. R Packag 1:15

20. Donaldson WF, Warren RF, Wickiewicz T (1985) A comparison of acute anterior cruciate ligament examinations. Initial versus examination under anesthesia. Am J Sports Med 13(1):5-10

21. Filbay SR, Grindem H (2019) Evidence-based recommendations for the management of anterior cruciate ligament (ACL) rupture. Best Pract Res Clin Rheumatol 33(1):33-47

22. Fok AW, Yau WP (2014) Associations between isolated bundle tear of anterior cruciate ligament, time from injury to surgery, and clinical tests. J Orthop Surg (Hong Kong) 22(2):209-213

23. Frank JM, Moatshe G, Brady AW et al (2017) Lateral meniscus posterior root and meniscofemoral ligaments as stabilizing structures in the ACL-deficient knee: a biomechanical study. Orthop J Sports Med 5(6):2325967117695756

24. Galway HR, MacIntosh DL (1980) The lateral pivot shift: a symptom and sign of anterior cruciate ligament insufficiency. Clin Orthop Relat Res 147:45-50

25. Geraets SE, Meuffels DE, van Meer BL et al (2015) Diagnostic value of medical history and physical examination of anterior cruciate ligament injury: comparison between primary care physician and orthopaedic surgeon. Knee Surg Sports Traumatol Arthrosc 23(4):968-974

26. Gürpınar T, Polat B, Polat AE et al (2019) Diagnostic accuracy of lever sign test in acute, chronic, and postreconstructive ACL injuries. Biomed Res Int 2019:3639693

27. Harbord RM, Deeks JJ, Egger M et al (2007) A unification of models for meta-analysis of diagnostic accuracy studies. Biostatistics 8(2):239-251

28. Hardaker WT, Garrett WE, Bassett FH (1990) Evaluation of acute traumatic hemarthrosis of the knee joint. South Med J 83(6):640-644

29. Huang $\mathrm{W}$, Zhang $\mathrm{Y}$, Yao $\mathrm{Z}$ et al (2016) Clinical examination of anterior cruciate ligament rupture: a systematic review and metaanalysis. Acta Orthop Traumatol Turc 50(1):22-31

30. Imhauser CW, Kent RN, Boorman-Padgett J et al (2017) New parameters describing how knee ligaments carry force in situ predict interspecimen variations in laxity during simulated clinical exams. J Biomech 64:212-218
31. Jackson JL, O'Malley PG, Kroenke K (2003) Evaluation of acute knee pain in primary care. Ann Intern Med 139(7):575-588

32. Jakob RP, Hassler H, Staeubli HU (1981) Observations on rotatory instability of the lateral compartment of the knee. Experimental studies on the functional anatomy and the pathomechanism of the true and the reversed pivot shift sign. Acta Orthop Scand Suppl 191:1-32

33. Jarbo KA, Hartigan DE, Scott KL et al (2017) Accuracy of the lever sign test in the diagnosis of anterior cruciate ligament injuries. Orthop J Sports Med 5(10):2325967117729809

34. Jonsson T, Althoff B, Peterson L et al (1982) Clinical diagnosis of ruptures of the anterior cruciate ligament: a comparative study of the Lachman test and the anterior drawer sign. Am J Sports Med 10(2):100-102

35. Kent RN, Imhauser CW, Thein R et al (2020) Engagement of the secondary ligamentous and meniscal restraints relative to the anterior cruciate ligament predicts anterior knee laxity. Am J Sports Med 48(1):109-116

36. Knight KL (2008) More precise classification of orthopaedic injury types and treatment will improve patient care. J Athl Train 43(2):117-118

37. Koga H, Nakamae A, Shima Y et al (2010) Mechanisms for noncontact anterior cruciate ligament injuries: knee joint kinematics in 10 injury situations from female team handball and basketball. Am J Sports Med 38(11):2218-2225

38. Kostov H, Arsovski O, Kostova E et al (2014) Diagnostic assessment in anterior cruciate ligament (ACL) tears. Pril (Makedon Akad Nauk Umet Odd Med Nauki) 35(1):209-218

39. Krakowski P, Nogalski A, Jurkiewicz A et al (2019) Comparison of diagnostic accuracy of physical examination and MRI in the most common knee injuries. Appl Sci 9(19):4102

40. Leblanc MC, Kowalczuk M, Andruszkiewicz N et al (2015) Diagnostic accuracy of physical examination for anterior knee instability: a systematic review. Knee Surg Sports Traumatol Arthrosc 23(10):2805-2813

41. Lee JK, Yao L, Phelps CT et al (1988) Anterior cruciate ligament tears: MR imaging compared with arthroscopy and clinical tests. Radiology 166(3):861-864

42. Lelli A, Di Turi RP, Spenciner DB et al (2016) The "Lever Sign": a new clinical test for the diagnosis of anterior cruciate ligament rupture. Knee Surg Sports Traumatol Arthrosc 24(9):2794-2797

43. Lichtenberg MC, Koster CH, Teunissen LPJ et al (2018) Does the lever sign test have added value for diagnosing anterior cruciate ligament ruptures? Orthop J Sports Med 6(3):2325967118759631

44. Liu SH, Osti L, Henry M et al (1995) The diagnosis of acute complete tears of the anterior cruciate ligament. Comparison of MRI, arthrometry and clinical examination. J Bone Joint Surg Br 77(4):586-588

45. Makki D, Mastan S, Ness D et al (2019) The role of clinical examination in predicting relevant MRI findings in acute knee injuries: a retrospective study. J Knee Surg 32(3):280-283

46. Marshall JL, Wang JB, Furman W et al (1975) The anterior drawer sign: what is it? J Sports Med 3(4):152-158

47. Massey PA, Harris JD, Winston LA et al (2017) Critical analysis of the lever test for diagnosis of anterior cruciate ligament insufficiency. Arthroscopy 33(8):1560-1566

48. McGee S (2002) Simplifying likelihood ratios. J Gen Intern Med 17(8):646-649

49. McQuivey KS, Christopher ZK, Chung AS et al (2019) Implementing the lever sign in the emergency department: does it assist in acute anterior cruciate ligament rupture diagnosis? A Pilot Study. J Emerg Med 57(6):805-811

50. Mitsou A, Vallianatos P (1988) Clinical diagnosis of ruptures of the anterior cruciate ligament: a comparison between the Lachman test and the anterior drawer sign. Injury 19(6):427-428 
51. Moher D, Liberati A, Tetzlaff J et al (2009) Preferred reporting items for systematic reviews and meta-analyses: the PRISMA statement. PLoS Med 6(7):e1000097

52. Moses B, Orchard J (2012) Systematic review: annual incidence of ACL injury and surgery in various populations. Res Sports Med 20(3-4):157-179

53. Mouton C, Magosch A, Pape D et al (2020) Ramp lesions of the medial meniscus are associated with a higher grade of dynamic rotatory laxity in ACL-injured patients in comparison to patients with an isolated injury. Knee Surg Sports Traumatol Arthrosc 28(4):1023-1028

54. Mulligan EP, McGuffie DQ, Coyner K et al (2015) The reliability and diagnostic accuracy of assessing the translation endpoint during the lachman test. Int J Sports Phys Ther 10(1):52-61

55. Olsson O, Isacsson A, Englund M et al (2016) Epidemiology of intra- and peri-articular structural injuries in traumatic knee joint hemarthrosis - data from 1145 consecutive knees with subacute MRI. Osteoarthritis Cartilage 24(11):1890-1897

56. Ouzzani M, Hammady H, Fedorowicz Z et al (2016) Rayyan-a web and mobile app for systematic reviews. Syst Rev 5(1):210

57. Peeler J, Leiter J, MacDonald P (2010) Accuracy and reliability of anterior cruciate ligament clinical examination in a multidisciplinary sports medicine setting. Clin J Sport Med 20(2):80-85

58. Phelan N, Rowland P, Galvin R et al (2016) A systematic review and meta-analysis of the diagnostic accuracy of MRI for suspected ACL and meniscal tears of the knee. Knee Surg Sports Traumatol Arthrosc 24(5):1525-1539

59. Reiman MP, Reiman CK, Décary S (2018) Accuracy of the Lever sign to diagnose anterior cruciate ligament tear: a systematic review with meta-analysis. Int J Sports Phys Ther 13(5):774-788

60. Reitsma JB, Glas AS, Rutjes AW et al (2005) Bivariate analysis of sensitivity and specificity produces informative summary measures in diagnostic reviews. J Clin Epidemiol 58(10):982-990

61. RStudio T. (2020) RStudio: Integrated Development for R. Rstudio Team, PBC, Boston, MA URL http://www.rstudio.com/.2020

62. Sandberg R, Balkfors B, Henricson A et al (1986) Stability tests in knee ligament injuries. Arch Orthop Trauma Surg 106(1):5-7

63. Sarimo J, Rantanen J, Heikkilä J et al (2002) Acute traumatic hemarthrosis of the knee. Is routine arthroscopic examination necessary? A study of 320 consecutive patients. Scand J Surg. 91(4):361-364

64. Scholten RJ, Opstelten W, van der Plas CG et al (2003) Accuracy of physical diagnostic tests for assessing ruptures of the anterior cruciate ligament: a meta-analysis. J Fam Pract 52(9):689-694

65. Shim SR, Kim SJ, Lee J (2019) Diagnostic test accuracy: application and practice using R software. Epidemiol Health. 41:e2019007

66. Smith C, McGarvey C, Harb Z et al (2016) Diagnostic efficacy of 3-T MRI for knee injuries using arthroscopy as a reference standard: a meta-analysis. AJR Am J Roentgenol 207(2):369-377
67. Solomon DH, Simel DL, Bates DW et al (2001) The rational clinical examination Does this patient have a torn meniscus or ligament of the knee? Value of the physical examination. JAMA 286(13):1610-1620

68. Song GY, Zhang H, Liu X et al (2017) Complete posterolateral meniscal root tear is associated with high-grade pivot-shift phenomenon in noncontact anterior cruciate ligament injuries. Knee Surg Sports Traumatol Arthrosc 25(4):1030-1037

69. Suero EM, Njoku IU, Voigt MR et al (2013) The role of the iliotibial band during the pivot shift test. Knee Surg Sports Traumatol Arthrosc 21(9):2096-2100

70. Swain MS, Henschke N, Kamper SJ et al (2014) Accuracy of clinical tests in the diagnosis of anterior cruciate ligament injury: a systematic review. Chiropr Man Therap 62:25

71. Tanaka M, Vyas D, Moloney G et al (2012) What does it take to have a high-grade pivot shift? Knee Surg Sports Traumatol Arthrosc 20(4):737-742

72. Thapa SS, Lamichhane AP, Mahara DP (2015) Accuracy of Lelli test for anterior cruciate ligament tear. J Inst Med 37(2):91-94

73. Torg JS, Conrad W, Kalen V (1976) Clinical diagnosis of anterior cruciate ligament instability in the athlete. Am J Sports Med 4(2):84-93

74. van Eck CF, van den Bekerom MP, Fu FH et al (2013) Methods to diagnose acute anterior cruciate ligament rupture: a meta-analysis of physical examinations with and without anaesthesia. Knee Surg Sports Traumatol Arthrosc 21(8):1895-1903

75. Wagemakers HP, Luijsterburg PA, Boks SS et al (2010) Diagnostic accuracy of history taking and physical examination for assessing anterior cruciate ligament lesions of the knee in primary care. Arch Phys Med Rehabil 91(9):1452-1459

76. Waldén M, Krosshaug T, Bjørneboe J et al (2015) Three distinct mechanisms predominate in non-contact anterior cruciate ligament injuries in male professional football players: a systematic video analysis of 39 cases. Br J Sports Med 49(22):1452-1460

77. Warren RF, Marshall JL (1978) Injuries of the anterior cruciate and medial collateral ligaments of the knee. A retrospective analysis of clinical records-part I. Clin Orthop Relat Res 136:191-197

78. Whiting PF, Rutjes AW, Westwood ME et al (2011) QUADAS-2: a revised tool for the quality assessment of diagnostic accuracy studies. Ann Intern Med 155(8):529-536

Publisher's Note Springer Nature remains neutral with regard to jurisdictional claims in published maps and institutional affiliations. 